\title{
A "ERA TECNOLÓGICA" ENTRE A REALIDADE E A FANTASIA: REFLEXÕES A PARTIR DOS CONCEITOS DE TRABALHO, EDUCAÇÃO E TECNOLOGIA EM MARX ${ }^{1}$
}

\author{
Domingos Leite Lima Filho ${ }^{2}$
}

\begin{abstract}
RESUMO:
Este texto analisa o conceito de "era tecnológica". É apropriado assumir esta terminologia? Quê pressupostos e consequiências estariam aí implicados? Nossa argumentação será apresentada em três tópicos: no primeiro faremos algumas considerações preliminares sobre o objetivo desta discussão, considerando especialmente o sentido amplo dos discursos sobre a tecnologia na atualidade; no segundo tópico apresentaremos os referenciais utilizados no presente trabalho quando nos referimos aos conceitos de "era tecnológica", de "realidade" e de "fantasia"; no terceiro tópico veremos as implicações desta abordagem, tendo como referência a articulação dos conceitos de trabalho, educação e tecnologia em Marx.

Palavras-chave: Era tecnológica; Filosofia da tecnologia; Trabalho e educação; Ciência e tecnologia; Determinismo tecnológico.

\section{THE " TECHNOLOGICAL AGE " BETWEEN REALITY AND FANTASY: REFLECTIONS FROM THE PERSPECTIVE OF LABOR, EDUCATION AND TECHNOLOGY IN MARX}

\begin{abstract}
:
The "technological age" between reality and fantasy: an analysis based on the concepts of work, education and technology in Marx This paper examines the concept of "technological age". It is appropriate to take this terminology? Assumptions and what consequences there would be involved? Our argument will be presented on three topics: first we make some preliminary remarks about the purpose of this discussion, especially considering the broad sense of the discourses about technology today and in the second topic we will present the benchmarks used in this paper when we refer to the concepts of "technological age", "reality" and "fantasy"; the third topic we will see the implications of this approach, with reference to the articulation of the concepts of work, education and technology in Marx.

Keywords: Technological age; Philosophy of technology; Work and education; Science and technology; Technological determinism.
\end{abstract}

No título do presente texto a expressão "era tecnológica" aparece entre aspas. Isto denota que esta denominação estará aqui sob discussão. Ou seja, é apropriado assumirmos esta terminologia? Quê pressupostos e conseqüências estariam aí implicados? Nossa argumentação será apresentada em três tópicos: no primeiro faremos algumas considerações preliminares sobre o objetivo desta discussão, considerando especialmente o caráter amplo dos discursos sobre a tecnologia na atualidade; no segundo tópico procuraremos apresentar os referenciais que adotamos no presente trabalho quando nos referimos aos conceitos de "era tecnológica", de "realidade" e de "fantasia"; no terceiro 
veremos as implicações da abordagem anterior e seus limites, tendo como referência a articulação dos conceitos de trabalho, educação e tecnologia em Marx.

\section{Algumas considerações preliminares: discursos acerca da tecnologia e da "era tecnológica"}

Sem dúvida, a tecnologia e o tecnológico, ou aquilo que genericamente passou a assim denominar-se, estão hoje presentes no cotidiano do trabalho, do lar, do lazer, no âmbito público e privado. Importa, portanto, atentar de inicio que estes termos de uso geral se tornam cada vez mais imprecisos e fluidos, como costuma ser comum em tudo aquilo que assume uma polifonia e uma polissemia.

Assim apresentados, discursos exaustivos, eventos, práticas e artefatos que se autoconferem o estatuto de tecnológico ou de tecnologia, "de ponta" ou de "última geração", parecem querer firmar uma espécie de "consenso" geral e generalizante acerca da importância da tecnologia nos dias atuais (são muitos os adjetivos complementares e o de ponta, de última geração, de melhor portabilidade, conectividade, interatividade e de tendência futura são sempre apresentados como os últimos e os melhores, até que o próximo discurso ou artefato seja enunciado). No entanto, quando se busca avançar um pouco além, logo se vê quão frágil é a sustentação dos enunciados sobre a tecnologia e sua importância, sobretudo aqueles que pretendem dar a esta categoria um caráter universal e a-histórico. Afinal, imersa nesta pretensa universalidade destituída de historicidade, a pergunta sobre o que é tecnologia poderia apresentar tantas respostas, com tantas relativizações, o que permitiria dizer que tecnologia é tudo, resultando assim em uma espécie de jogo de soma zero.

Nesse sentido, o que tenho por intenção neste artigo é discutir se e em quê medida as categorias conceituais caudatárias da tradição filosófica e epistemológica do materialismo histórico, nas formulações originárias de Karl Marx, poderiam nos orientar nesta discussão acerca da conceituação da tecnologia e de sua produção e apropriação, considerando que tecnologia é algo importante e amplo demais para ser deixado meramente ao encargo dos tecnólogos, dos tecnocráticos, dos tecnofílicos ou dos tecnofóbicos.

Sabe-se que Marx foi, ele mesmo, um dedicado e meticuloso estudioso da tecnologia. Uma consulta a sua obra nos mostrará que dedicou cerca de 1500 páginas, distribuídas em 23 cadernos redigidos entre 1861 e 1863, em que analisa desde o emprego das forças naturais ao desenvolvimento das máquinas e da ciência, suas aplicações aos processos produtivos e a produção da mais-valia relativa. Parte deste material foi posteriormente organizada e deu origem aos livros II e III de O Capital e, mais adiante às Teorias da mais-valia (que deveriam formar o livro IV), e que se publicaram postumamente em 1885 e 1894 por Friedrich Engels e em 1905 por Karl Kautsky, respectivamente, posto que Marx, em vida, havia publicado apenas o livro I de O Capital, em 1867 (BOLCHINI, 1980).

Em muitas passagens Marx insistia que a tecnologia constituía assunto de interesse não somente de especialistas, mas da sociedade de modo geral. Embora utilizado em vários trechos de sua obra, devemos recordar que o termo tecnologia não tinha, então, uma utilização tão difundida e tão ampla como nos dias atuais. Pode-se tomá-lo à época, e especificamente nos textos de Marx, como relacionado às expressões "desenvolvimento 
das forças produtivas", "maquinaria", "indústria moderna" ou ainda "produção de maisvalia relativa". No entanto, não deixando dúvidas sobre quaisquer interpretações reducionistas de natureza aplicativa, instrumental ou economicista, o autor afirma com clareza a centralidade social da tecnologia quando a ela se refere literalmente: "A tecnologia revela o modo de proceder do homem para com a natureza, o processo imediato de produção de sua existência e, com isso, também o processo de produção de suas relações sociais e das representações intelectuais que delas decorrem" (MARX, 1978, p. 425).

Portanto, para Marx (1972), as novas forças produtivas, ao longo da história da humanidade, não emergem exogenamente ou misteriosamente como um deus ex machina, mas sim como resultado dialético de um processo histórico mais amplo de desenvolvimento em interação e contradição entre as forças produtivas e as relações sociais de produção existentes (ROSENBERG, 2006), conforme podemos observar neste trecho dos Grundrisse em que aponta diretamente:

Deve-se ter em mente que as novas forças produtivas e as novas relações de produção não se desenvolvem a partir do nada, nem caem do céu, nem do útero da auto-impositiva Idéia; mas do interior do e em antítese ao estágio de desenvolvimento da produção e às relações de propriedade tradicionais recebidas como herança (MARX apud ROSENBERG, p. 73, 2006).

Nesse sentido, argumentarei que as formulações conceituais originárias de Marx sobre a tecnologia, em suas articulações com as categorias trabalho e educação, seguem sendo, na atualidade, um arcabouço teórico e metodológico consistente e fundamental para a investigação das relações sociais de produção nas quais se inserem a tecnologia, suas ramificações e suas representações.

\section{Sobre o significado de "era tecnológica" e de "realidade e fantasia"}

Do meu ponto de vista, seja para explicar o título do texto, seja como introdução ao arcabouço teórico-metodológico aqui apresentado, faz-se necessário enfrentar, preliminarmente, duas questões. A primeira delas, relativa à pertinência e especificidade da denominação "era tecnológica"; a segunda, relativa às relações dicotômicas entre a tecnologia e suas representações, relacionadas por sua vez aos conceitos de realidade e aparência desenvolvidos por Marx.

No que se refere à primeira questão, é importante ressaltar que tornou-se lugar comum, parece ser uma espécie de consenso geral nesta época histórica que os pósmodernos afirmaram ser o fim das meta-narrativas e dos meta-projetos societários, a afirmação de que vivemos uma "revolução científica e tecnológica" ou de que vivemos a "era tecnológica"; para tanto, alguns advogam, inclusive, a necessidade de uma "alfabetização tecnológica" (WINNER, 1987). A tecnologia e a revolução tecnológica são, assim, apresentadas discursivamente como meta-categorias. Em um mundo que estava "proibido" pelo léxico dos pós-modernos a existência de meta-categorias, enfim, elas se apresentam. Esta constatação nos parece interessante porque evidencia que a filosofia pósmoderna, que é uma filosofia extremamente negativa, apresenta suas contradições e insuficiências (EAGLETON, 1998). Não me refiro ao negativo em um sentido moral, mas 
em um sentido histórico, ao aspecto de negação generalizada proposta pelos pós-modernos, quando de sua recusa à possibilidade de construção de projetos societários em que os sujeitos sociais, com base em seu passado e presente, tendo em vista as contradições, os limites e as possibilidades com os quais se defrontam, possam articular suas concepções, ações, lutas e, enfim, projetos societários e civilizatórios de futuro, para além da ordem vigente do capital (MÉSZAROS, 2002). A propósito, lembremos que toda a vasta produção editorial extremamente especulativa que caracterizou a chegada do chamado "novo milênio" e que coincide com a produção pós-moderna mais extremada, ocorrida, sobretudo, nas duas últimas décadas do século XX e em grande parte da primeira década deste século, esteve centrada, entre outros, na argumentação acerca da impossibilidade dos projetos, da história ou da teoria, defendendo a idéia do capitalismo global como horizonte último da humanidade, situando-se nesse campo as formulações de FUKUYAMA (1992) sobre o "fim da história" e outras teses da chamada "agenda pós-moderna", nas quais é possível situar ainda as formulações de BAUDRILLARD (1996) e LYOTARD (1990), entre outros.

A “agenda pós-moderna" traz a concepção de mundo fragmentado e indeterminado e a rejeição a qualquer discurso totalizante, qualquer meta-narrativa e quaisquer teorias ou projetos políticos abrangentes e universalistas. Ademais, tal "agenda" ou concepção, sempre referida como rejeição à modernidade, conserva, especialmente, o mesmo pressuposto fundamental desta, qual seja o de considerar as leis de movimento especificamente capitalistas como se fossem leis universais da história, produzindo, em teoria, a invisibilidade histórica das relações sociais capitalistas, isto é, sua naturalização (WOOD, 2001).

A afirmação de que vivemos uma era tecnológica não deve ser desconsiderada, pode, a meu ver, em alguma medida ser considerada pertinente; o que discuto é se tal categorização (o tecnológico) é especifico desta era que nos toca viver; já no que se refere ao substantivo revolução, partindo do conceito de que revolução pressupõe ruptura da ordem social anterior, considero que não existem rupturas no sistema de relações sociais vigentes que nos permitam caracterizar a dita "era tecnológica" como o advento de uma revolução, ainda que muitos a caracterizem como a terceira ou a quarta "revolução industrial". Lembremos que, conforme escreveu Marx (1977a), "A história se repete, a primeira vez como tragédia e a segunda como farsa".

Nesse sentido, é interessante observar a afirmação de Álvaro Vieira Pinto, sobre a possível existência de uma concepção tecnológica da sociedade, em entrevista publicada pela Revista de Cultura, n. 6, ano 64, agosto de 1970, Editora Vozes. Pinto, em uma afirmação longa, porém extremamente incisiva e atual, afirma:

Não existe "concepção tecnológica da sociedade" como conceito respeitável, mas apenas como expressão literária, usada por articulistas ou sociólogos impressionistas. A questão desloca-se para a compreensão da técnica, a respeito da qual vem-se generalizando os mais confusos e simplórios equívocos. A técnica é coetânea da existência humana, inerente a ela, nada tem de substantivo, não é uma hipótese, mas um modo de ser do homem, e por isso não há razão em designar, como parece ser o intuito da pergunta, a sociedade atual como "tecnológica". Todas as sociedades que até agora existiram foram tecnológicas, no sentido de serem dependentes das técnicas produtivas, materiais e ideais, de que dispunham, inclusive as de administração e governo. O que seria de espantar é que assim não fosse. ... A idéia de estarmos vivendo uma época de esplendor tecnológico é inteiramente ingênua, pois o mesmo 
pensaram os homens de todas as fases históricas precedentes em relação ao seu tempo. ... Toda época histórica dá origem sempre às utopias que nela podem florescer (PINTO, 1970).

Estas observações de Pinto a respeito da técnica como inerente ao ser social nos remetem, por outro lado, ao pensamento de Herbert Marcuse, que em um ensaio escrito em 1941, intitulado "Algumas implicações sociais da tecnologia moderna", faz distinção entre tecnologia e técnica. Nesse sentido, "a tecnologia é vista como um processo social no qual a técnica propriamente dita (isto é, o aparato técnico da indústria, transportes, comunicação) não passa de um fator parcial" (MARCUSE, 1999, p. 73). A intenção clara do autor é distinguir o sistema tecnológico de instrumentos técnicos de seu uso, considerando o caráter amplo do primeiro e o sentido estrito do segundo termo. Considera, portanto, que a tecnologia "é assim, ao mesmo tempo, uma forma de organizar e perpetuar (ou modificar) as relações sociais, uma manifestação do pensamento humano e dos padrões de comportamento dominantes, um instrumento de controle e dominação (MARCUSE, 1999, p. 73).

É que, para Marcuse (1979), progresso técnico, ciência e tecnologia são necessidades e produções objetivas tanto para o capital quanto para o trabalho, porém suas possibilidades e limites são condicionados social e historicamente, de modo que é impossível falar genericamente em desenvolvimento tecnológico ou indistintamente e mecanicamente associar desenvolvimento tecnológico a desenvolvimento social (LIMA FILHO e QUELUZ, 2005). Faz-se necessário, portanto, ter em conta as dimensões infraestruturais e superestruturais da sociedade e, considerando os dos marcos contraditórios e limites característicos das relações capitalistas de produção, Marcuse questiona: "Porque uma sociedade estruturalmente injusta vai aprofundar as possibilidades de superação da injustiça que oferecem os meios técnicos que essa mesma sociedade produz e controla?" (MARCUSE, 1979, p. 37).

Observa-se, assim, que Marcuse, mantendo uma perspectiva crítica e dialética com relação ao processo de hegemonia da sociedade industrial, sua racionalidade instrumental e seus mecanismos de controle e padronização social, não se deixa levar pelo otimismo tecnocrático. Tampouco, assume uma postura anti-industrialista ou de pessimismo tecnofóbico. $\mathrm{O}$ autor interpreta a tecnologia e os artefatos técnicos como produção social e histórica e neles vê, ao mesmo tempo, obstáculos e potencialidades ao pleno desenvolvimento do ser social: por um lado, sistemas de dominação, por outro, possibilidades de fruição, podendo "promover tanto o autoritarismo quanto a liberdade, tanto a escassez quanto a abundância, tanto o aumento quanto a abolição do trabalho árduo (MARCUSE, 1999, p. 74).

No que diz respeito à segunda questão, relativa, sobretudo, às dicotomias entre apresentações e representações da tecnologia, penso que os conceitos de realidade e alienação desenvolvidos por Marx são de grande utilidade para uma abordagem adequada desta problemática.

Como já destaquei no início do texto, não desconheço que o impactante desenvolvimento da produção, da automação, de produtos ditos tecnológicos, ou enfim, da tecnologia, assume nos dias atuais uma dimensão marcante, se fazendo presente em múltiplas dimensões da vida social em seus diversos âmbitos. Assim a tecnologia, ou o 
que se representa como tecnologia, assume papel central na sociabilidade, ou seja, na produção da realidade e do imaginário. No entanto, ao lado dessa centralidade real, comparece um fetiche de representações, derivando daí a observação e experimentação imediata e fenomenológica da "sociedade do espetáculo" (DEBORD, 1997), que parece provocar uma estranha mescla de fascínio e mal-estar ante as possibilidades e limites, conquistas e impactos atribuídos à tecnologia.

O que tem isso de realidade e de fantasia? Talvez seja necessário ousar ultrapassar a barreira do imediato, do sensível, do aparente. Como disse Marx (1977), toda a ciência e a filosofia seriam inúteis, caso a manifestação fenomênica (aparência) e a essência do objeto coincidissem diretamente.

Esta é a síntese da epistemologia de Marx, ou seja, a construção do conhecimento como processo de aproximação à realidade. Para nosso autor, em um primeiro nível estão as formas imediatas, que apenas "refletem" de forma direta, como fenômeno, as relações essenciais. Para nos aproximarmos da essência interna, ou subjacente dos objetos da realidade (lembremos que os objetos não têm existência isolada), faz-se necessário a produção, no pensamento, de uma representação adequada de suas conexões internas e externas -isto é, das múltiplas e, por vezes, contraditórias mediações, que ocorrem no processo-, o que exige trabalho teórico e transformação conceitual, e não uma simples observação e réplica passiva dos fenômenos. Pressupõe, ademais, a não redutibilidade dos objetos ao conhecimento, o que implica o caráter socialmente produzido e, por conseguinte, historicamente relativo desse conhecimento. Enfim, o conhecimento possível da realidade, na epistemologia marxista se queremos assim dizer, não é meramente um processo lógico e imediato, mas onto-metodológico, mediato, aproximativo, provisório e histórico.

Prosseguindo, acrescentarei que as representações que se produzem acerca da tecnologia estão, portanto, mediatizadas pelas relações sociais vigentes que, na dominância das relações capitalistas de produção convertem trabalho, ciência e tecnologia em mercadoria e, dessa forma, são convertidas de sua significação concreta de uso e utilidade social, na forma geral e abstrata de troca que caracteriza a alienação da conversão em mercadoria. Derivam daí as fantasias, ou seja, o fetichismo da tecnologia, que como o fetichismo geral da mercadoria, nada mais é que a atribuição de certas qualidades ou características aos objetos materiais pelas relações sociais dominantes e que aparecem como se lhes pertencessem naturalmente (mais adiante voltarei a essa questão, posto que é uma base para a compreensão das concepções instrumentais e deterministas da tecnologia).

\section{Sobre a articulação dos conceitos de trabalho, educação e tecnologia em Marx}

Para avançar na discussão acerca da conceituação da tecnologia e de sua produção e apropriação, tendo por base as categorias do materialismo histórico, é importante observar dois aspectos fundamentais: (i) a relação trabalho e educação; (ii) a relação trabalho, ciência e tecnologia.

Para a análise dos processos e mediações sociais que envolvem estas duas relações fundamentais nosso ponto de partida levará em conta que estamos imersos em um sistema de relações sociais, a época histórica que nos toca viver e, nessa perspectiva, é necessário considerar que no desenvolvimento das relações sociais capitalistas de produção verificouse a intensificação da presença da ciência e da tecnologia como forças intelectuais e materiais do processo produtivo, como forma de potencialização das forças produtivas, o 
que permitiu a elevação da produtividade do capital e o aumento da riqueza produzida pela sociedade (MARX, 1972). Portanto, ciência e tecnologia estão socialmente referenciadas, relacionadas a uma época histórica e a determinadas concepções de mundo ou ideologia, o que implica em não considerar nenhuma pretensa posição de neutralidade acadêmicocientífica. No entanto, há que considerar que as relações sociais de produção capitalistas não são naturais, nem eternas, mas históricas, e como tal, sujeitas a conflitos, contradições, limites e possibilidades de afirmação ou de superação.

Comecemos a análise, portanto, pela relação entre trabalho e educação. Consideremos, inicialmente, o trabalho em sua dimensão ontológica, categoria constitutiva do ser social (Lukács,1981). Nesta dimensão, o trabalho é processo coletivo mediante o qual o ser social produz as condições gerais da existência. Ao produzir tais condições, em confronto com a natureza e com as suas próprias condições históricas e sociais - o que envolve um processo teleológico mediante o qual atua, conforme suas necessidades e em confronto com as possibilidades e as condições em que se encontra - o ser que trabalha fazse social, sujeito da construção de si, do mundo e das relações sociais, tanto de sua produção material, quanto intelectual (Marx, 1978).

No entanto, é necessário compreender o trabalho em sua dupla dimensão, estabelecendo a diferença entre a dimensão ontológica descrita e o seu desenvolvimento histórico, que o faz assumir características específicas e determinadas conforme as diferentes relações sociais de produção construídas ao longo da história da humanidade. Neste aspecto, sob a dominância das relações capitalistas de produção, o trabalho assume um duplo aspecto: produtor de condições necessárias à vida, portanto, à satisfação das necessidades humanas, valor de uso; produtor de mercadorias, portanto, valor de troca, necessário ao processo de reprodução e valorização do capital. Esta dimensão contraditória do trabalho representa a sua forma histórica degradada e alienada sob o domínio das relações capitalistas de produção.

Considerando a centralidade do trabalho nas dimensões ontológicas e históricas, nas quais se constituem processos contraditórios de construção e de alienação de sujeitos sociais, é que podemos entender a categoria trabalho como fonte de produção e apropriação de conhecimentos e práticas.

Quanto à segunda relação, ou seja, quanto à relação entre trabalho, ciência e tecnologia, compreendemos que o processo imbricado de construção da ciência e da tecnologia é compreendido como integrado ao processo de desenvolvimento de todo um complexo conjunto de práticas sociais e históricas, de saberes tácitos e de conhecimentos sistematizados que permitem a satisfação das necessidades humanas, ao mesmo tempo em que se produzem continuamente novas necessidades, mediante extensão das possibilidades e potencialidades. Assim, o desenvolvimento científico e tecnológico resulta do o processo de produção e apropriação contínua de conhecimentos, saberes e práticas pelo ser social no devir histórico da humanidade. A ciência e a tecnologia são entendidas, portanto, como construções sociais complexas, forças intelectuais e materiais do processo de produção e reprodução social. Como construções sociais, participam e condicionam as mediações sociais, porém não determinam por si só a realidade, não são autônomas, não são neutras e nem somente experimentos, técnicas, artefatos ou máquinas; constituem-se na interação ação-reflexão-ação de práticas, saberes, conhecimentos e relações de poder e propriedade: são, portanto, relações sociais objetivadas.

Deste entendimento sobre estas duas relações enunciadas, derivam duas posições: 
Primeira posição: entendo que não há uma dissociação real entre os processos educativos -ou seja, a produção intelectual- e os processos produtivos -isto é, a produção material da vida. Pelo contrário, parto da premissa de integração na relação Trabalho e Educação. Embora nas sociedades contemporâneas sob a hegemonia do capital o ato de educar e o ato de produzir sejam tomados em locais distintos e instituições específicas (a escola/universidade e o local ou atividade de trabalho), considero que estas duas esferas da sociabilidade são interdependentes. Na minha compreensão, a relação que deveria haver entre elas não deveria ser a subordinação ou redução da escola ao que requer a produção (na educação usualmente dirigida aos trabalhadores, diz-se vamos formar para o trabalho, ou vamos formar para o mercado), nem deveria ser de dissociação (quando normalmente se faz uma cultura letrada às elites), mas de integração entre trabalho e educação. Isso, óbvio, é uma questão complexa e tem a ver com o modelo de sociedade vigente e, sobretudo, com a necessária distinção entre considerar o trabalho em sua dimensão ontológica, atividade mediadora entre o ser, os demais e o meio, pela qual se constroem as condições materiais e intelectuais da vida, ou considerar o trabalho em sua dimensão reduzida e subordinada à sociedade capitalista, reduzido à mercadoria força-de-trabalho mediante consumo em profissão e determinado emprego.

Segunda posição: da mesma forma que a primeira relação, não concebo ciência e tecnologia dissociadas das relações sociais de produção, mais sim condicionadas por estas. Ou seja, o que defendo é que situemos a ciência e tecnologia em um sistema de referências senão elas viram meras abstrações, caso sejam tomadas como "categorias em si", e tornamse incognescíveis, ou, pior ainda, elementos do senso comum. É necessário considerá-las na dimensão "para si"; ou seja, conhecer o seu significado no sistema de relações sociais vigente, de modo geral, e de modo mais especifico, considerando a questão a partir da perspectiva dos trabalhadores.

Talvez tenha sido por esta razão que analisando estas contradições e como elemento da luta política dos trabalhadores, Marx tenha utilizado o termo educação tecnológica, situando-o no próprio corpo teórico de sua crítica às relações sociais capitalistas de produção. Nesse sentido, a educação tecnológica teria como princípio a união da instrução com o trabalho material produtivo (no sentido geral de trabalho social útil) o que, para Marx, seria o germe da educação do futuro.

Já no Manifesto Comunista (1848) o pensador alemão assinalava a importância, para a classe trabalhadora, da luta pela educação pública e gratuita de todas as crianças, a abolição do trabalho das crianças nas fábricas e a combinação da educação com a produção material (Marx, 1988). No texto escrito para o Primeiro Congresso da Associação Internacional dos Trabalhadores (1866) Marx traria uma definição mais completa acerca da questão educacional para os trabalhadores, entendendo-a composta pelas dimensões intelectual, corporal e tecnológica, sendo esta última a que trata dos "princípios gerais e de caráter científico de todo o processo de produção e, ao mesmo tempo, inicia as crianças e adolescentes no manejo de ferramentas elementares dos diversos ramos industriais" (Marx, 1983, p.60). No texto d O Capital, em uma passagem marcada pelo otimismo, assinalava que "a conquista inevitável do poder político pela classe operária vai introduzir o ensino teórico prático da tecnologia nas escolas do povo" (Marx, 1978, p. 553).

Por fim, poderíamos inferir que a educação, orientada por tal perspectiva do trabalho, seria importante meio de refutar a "ideologia da técnica". Isto porque situaria a tecnologia no plano das ações humanas concretas, orientadas ao processo de humanização do mundo, mediante sua ação como sujeito concreto da história, em contraposição às 
abstrações que acabam por situar a discussão no nível do senso comum e a conferir um fetiche à técnica e à tecnologia em si mesmas, do que resulta o processo de ideologização. Pois é justamente neste processo de ideologização que se apóia o pragmatismo, que opera uma espécie de sacralização ou demonização da tecnologia. Essa operação retira a tecnologia do contexto social e cultural em que é produzida e apropriada, constituindo-se assim a base fundante do determinismo tecnológico, onde a "agencia é dada à própria tecnologia e aos seus atributos intrínsecos", onde temos poucas alternativas às suas exigências inerentes, pois o "desenvolvimento tecnológico é percebido como uma força autônoma, completamente independente de constrições sociais" (SMITH \& MARX, 1994, p. 2). Determinismo tecnológico que caracteriza a matriz de racionalidade instrumental, que centra sua análise no artefato, dissociado de sua produção social, portanto, uma matriz teórica que conjuga ao mesmo tempo acepções conceituais da tecnologia referidas ao senso comum e à ideologização da técnica.

Em nossa crítica a essa perspectiva instrumental, apresentamos a perspectiva crítico-relacional da tecnologia pela qual concluímos que se trata de restituir a tecnologia aos contextos sociais e culturais nos quais é produzida e apropriada historicamente. Partindo do pressuposto da existência de uma sociedade histórica e concretamente determinada, em que as relações sociais capitalistas detêm a hegemonia na atualidade porém, sem considerar tais relações como naturais, eternas, ou isentas de contradições e de movimentos de resistência e de construção de novas hegemonias no seio da hegemonia existente e em contradição com ela - é que podemos avançar na discussão sobre a conceituação de tecnologia e de sua produção, apropriação e inter-relação com os processos de transformação social. E, nesse processo, considerar as perspectivas, limites e possibilidades da tecnologia e da educação na construção de uma nova sociabilidade, não como determinismo tecnológico, mas como possibilidade histórica, utopia construída a partir da ação dos sujeitos sociais (LIMA FILHO e QUELUZ, 2005).

\section{Referências:}

BAUDRILLARD, J. The perfect crime. N. York, London. Verso, 1996.

BOLCHINI, Piero. Karl Marx: capital y tecnología. México, Terra Nova, 1980.

DEBORD, Guy. A sociedade do espetáculo. São Paulo, Contraponto, 1997.

EAGLETON, Terry. As ilusões do pós-modernismo. São Paulo, Jorge Zahar, 1998.

FUKUYAMA, F. El fin de la historia y el último hombre. Barcelona, Planeta, 1992.

LIMA FILHO, D. L.; QUELUZ, G. L. A tecnologia e a educação tecnológica: elementos para uma sistematização conceitual. Revista Educação \& Tecnologia, Belo Horizonte, v. 10, n.1, p. 19-28, jan/jun 2005.

LUKÁCS, G. O trabalho. Per uma ontologia dell'essere sociale. V. 2, Roma, Riuniti, 1981.

LYOTARD, J. O pós-modernismo. Rio de Janeiro, José Olympio Ed., 1990.

MARCUSE, H. Tecnologia, guerra e fascismo. São Paulo, UNESP, 1999.

MARCUSE., H. La angustia de prometeo (25 tesis sobre técnica y sociedad). In: El Viejo Topo, n. 37,1979, Barcelona. 
MARX, K. \& Engels, F. Manifesto Comunista, São Paulo, Global, 1988.

MARX, Karl. Elementos Fundamentales para la Crítica de la Economia Politica (Grundisse). México, Siglo XXI, 1972.

MARX, Karl. Instruções aos delegados do Conselho Central Provisório. In: MARX \& ENGELS. Textos sobre educação e ensino. São Paulo, Moraes, 1983 pp. 59-61.

MARX, Karl. O 18 brumário de Luís Bonaparte. In: MARX, K.; ENGELS, F. Textos, v. III. São Paulo, Edições Sociais, 1977.

MARX, Karl. O Capital, L. 1, v. 1, São Paulo, Difel, 1978.

MARX, Karl. O Capital, L. 2, v. 3, São Paulo, Difel, 1977a.

MÉSZÁROS, I. Para além do capital. São Paulo, Boitempo, 2002.

PINTO, A. V. Entrevista. Revista de Cultura, n. 6, ano 64, Rio de Janeiro, Vozes, 1970.

PINTO, A. V. O conceito de tecnologia. Rio de Janeiro, Contraponto, 2v, 2005.

ROSSI, Paolo. Naufrágios sem espectador: A idéia de Progresso, São Paulo: UNESP, 2000.

ROSENBERG, N. Por dentro da caixa-preta: tecnologia e economia. Campinas, Unicamp, 2006.

SMITH, Merritt Roe \& MARX, Leo. Does Technology Drive History?: The Dilemma of Technological Determinism, Cambridge: MIT Press, 1994.

WINNER, L. (1987). La balena y el reactor - una búsqueda de los límites en la era de la alta tecnología. Barcelona, Gedisa.

WOOD, E. A origem do capitalismo. São Paulo, Jorge Zahar, 2001.

\footnotetext{
${ }^{1}$ Texto apresentado na Mesa redonda Trabalho, Educação e Sociabilidade, do VII Seminário do Trabalho, UNESP, Marília, 25 de maio de 2010.

2 Doutor em Educação, Professor do Programa de Pós-Graduação em Tecnologia e do Departamento Acadêmico de Eletrotécnica da Universidade Tecnológica Federal do Paraná - UTFPR. Coordenador do Grupo de Estudos e Pesquisas em Trabalho, Educação e Tecnologia - GETET.
}

Artigo recebido em: 30/05/2010

Aprovado em: 08/06/2010 